\title{
Linear array of complementary metal oxide semiconductor double-pass metal micromirrors
}

\author{
Johannes Bühler \\ Franz-Peter Steiner \\ ETH Zürich \\ Physical Electronics Laboratory \\ HPT H6 \\ CH-8093 Zürich, Switzerland \\ mail: buehler@iqe.phys.ethz.ch \\ Roland Hauert \\ Swiss Federal Laboratories for Materials \\ Testing and Research (EMPA) \\ Ueberlandstrasse 129 \\ $\mathrm{CH}-8600$ Dübendorf, Switzerland \\ Henry Baltes \\ ETH Zürich \\ Physical Electronics Laboratory \\ HPT H6 \\ $\mathrm{CH}-8093$ Zürich, Switzerland
}

\begin{abstract}
Low-cost linear arrays of deflectable micromirrors using a CMOS-compatible process to define both on-chip circuitry and the mirror structure are presented. The mirrors consist of the CMOS second metal layer deposited in two successive passes in order to establish a thick metal layer for the stiff mirror plate as weli as a thin one for the flexible hinges. The mirrors are released by sacrificial aluminum and oxide etching. Supercritical point drying is performed in order to avoid sticking of the mirrors to the substrate. The mirrors are electrostatically deflected by biasing the address electrodes implanted into the substrate underneath the mirror plate. Full angular deflection by $\pm 4.8 \mathrm{deg}$ of a $30 \times 40-\mu \mathrm{m}^{2}$ plate is achieved with a driving voltage of $11 \mathrm{~V}$. On-chip circuitry adjacent to each mirror allows one to address the pixels with $5-V$ data pulses. The reflectance of the aluminum surface for wavelengths between $400^{\circ}$ and $700 \mathrm{~nm}$ was measured to be $83 \%$ to $89 \%$. The mirror surface was further characterized using Auger spectroscopy, showing that no optically relevant surface modifications occur during postprocessing. The surface rms roughness measured by atomic force microscopy is on the order of $25 \mathrm{~nm}$. (c) 1997 Society of Pholo-Oplical Instrumentation Engineers. [S0091-3286(97)00805-2]
\end{abstract}

Subject terms: micro-opto-electro-mechanical systems; deformable micromirror; torsional micromirror; micromirror array; spatial light modulator; surface microma. chining; double-pass metal.

Paper MEM-08 received Nov. 6, 1996; revised manuscript received Jan. 8, 1997; accepted for publication Jan. 16, 1997.

\section{Introduction}

Linear arrays of deflectable micromirrors are of substantial interest as light modulators in printers and scanning de'ces. The integration of micromechanical and electronic vices on a single chip is indispensable in order to achieve large arrays with individually addressable pixels. Previously, electrostatically driven torsional mirror arrays were demonstrated using specific actuator processes, ${ }^{1-3}$ some of them on top of a CMOS process. Others ${ }^{4-6}$ introduce additional layers, such as polysilicon, for purely mechanical purposes into the standard process. In the case of polysilicon, however, the additional thermal budget from the deposition and annealing has to be considered for the fabrication of the electronic devices.

The contrast ratio of micromirror arrays is limited by the filling factor of the pixels, i.e., the mirror-to-mirror spacing divided by the pixel size. In applications using linear arrays, the optically relevant (active) area is a narrow line masking off the adjacent space where the optically inactive components of the light modulator can be placed. Consequently, the electronic components of each pixel and the etch holes can be designed adjacent to the mirror structure and do not have to be integrated into the area of the pixel. Therefore, the high level of process integration of conventional 2-D micromirror arrays is not required for a linear array, and a more efficient fabrication process is gaining interest.
A low-cost mirror fabrication needs to be based on a process as close to the standard IC process as possible with a minimum number of additional masks and process steps required. Mirror arrays can be fabricated at low cost when the IC process layers can be used for multiple purposes: to build up the mirror structure and the sacrificial layers that allow to release the mirror. as well as to fabricate the onchip circuitry. In our approach. the most critical and expensive fabrication steps - layer deposition and patterning are all done within the cost-effective IC process, and the postprocessing only consists of a low-cost, sacrificial-layer wet etching sequence to release the mirrors. The individual liyer thicknesses required for the flexible as well as for the stiff parts of the mechanical derice are obtained by depositing and patterning the mirror material in two passes as described in Sec. 2

Aluminum is commonly available in standard processes as interconnect metal and shows a high optical reflectance. It is thus the favorite micromirror material. However, the progress in IC technology led to an optimization in the efectrical but not necessarily in the optical properties of aluminum metallizations. Therefore, the surface characteristics and optical properties of various aluminum metallizations to be used in our devices were investigated (Sec. 3), and the results are discussed in Sec. 4

\section{Device Fabrication}

The electrostatically actuated torsional micromirror consists of a stiff, free-standing mirror plate suspended from 
The mirror plate acts as the upper electrode, and $n+$ implants within the $p$-epitaxial silicon located below each mirror wing serve as individually driven lower address electrodes (Fig. 1). Landing electrodes iniplanted the same way underneath the free edges of the mirror prevent it from sticking when the plate touches the substrate in the fully deflected state. Metal 1 and the intermetal (via) silicon dioxide are used as sacrificial layers and define the gap between the mirror and the lower electrodes. For good optical properties, good planarity of the mirror plate is essential, which is achieved by implanting the lower electrodes and thus avoiding any topographical step underneath the mirror.

The micromirror array and integrated on-chip circuitry ire fabricated using the 1.6- $\mu \mathrm{m}$ double-metal CMOS process (called DIMOSO1) at Delft University of Technology, The Netherlands. The process flow (Fig. 2) included the double-pass metal 2, a top photoresist layer instead of the silicon nitride passivation to protect the bonding pads and actuators during the postprocessing, and the dicing of the wafers.

The postprocessing consists of an etch sequence (Fig. 3) to release the actuators with no photolithographic step required:

1. The metal 1 sacrificial layer is wet-elched in a standard aluminum etch solution to undercut the structure in large lateral dimensions with high selectivity over the dielectrics and photoresist protecting the aluminum actuator.

2. The $1-\mu m$-thick intermetal silicon dioxide protection is removed by a dip in Pad-etch for typically $16 \mathrm{~min}$. Pad-etch is an ammonium fluoride etchant of sufficient selectivity to aluminum consisting of $13.5 \mathrm{wt} \%$ $\mathrm{NH}_{4} \mathrm{~F}, 31.8 \mathrm{wt} \%$ acetic acid, $4.2 \mathrm{wt} \%$ ethylene glycole, and water. ${ }^{\not}$ The samples are then rinsed for $10 \mathrm{~s}$ in deionized (DI) watter.

3. In order to ensure a high processing yield, the natural oxide on top of the aluminum surfices is enhanced by immersing the chips in a wet chemical oxidant after the pad-etch step. A period of $10 \mathrm{~min}$ in chromic acid or $30 \mathrm{~min}$ in hydrogen peroxide is sufficient to prevent the aluminum trom being chemically attacked by the subsequent thorough rinse in DI water.

4. The top photoresist passivation is removed by acetone (2 min) and a final rinse in DI water.

5. Supercritical point drying using $\mathrm{CO}_{2}$ in a commercial Baltec CPD030 system prevents sticking of mirrors to the substrate due to adhesion during drying. Acetone is used as the intermediate liquid between deionized water and the liquid $\mathrm{CO}_{2}$.

Linear arrays of 16 pixels were integrated with an inverter next to the mirror to drive each pixel individually (Fig. 4). The size of the mirror plate and the air gap between mirror and lower electrodes were chosen to be $30 \times 40 \mu \mathrm{m}^{2}$ and $1.7 \mu \mathrm{m}$, respectively, resulting in a maximum mirror deflection of $\pm 4.8 \mathrm{deg}$. The mirror suspensions were $0.3 \mu \mathrm{m}$ thick, $15 \mu \mathrm{m}$ long. and $2.4 \mu \mathrm{m}$ wide. setting the threshold voltage for the full deflection to $11 \mathrm{~V}$.
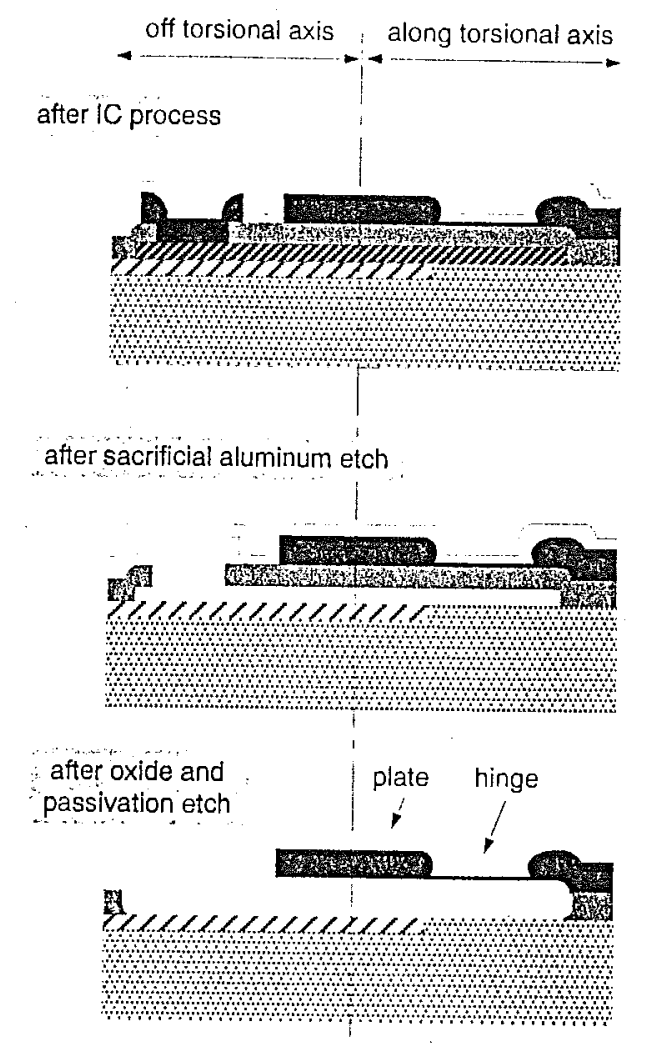

.... photoresist passivation

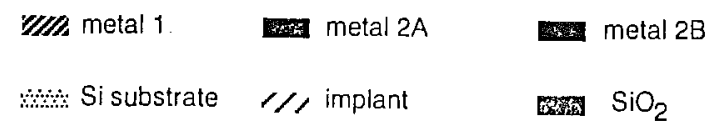

Fig. 3 Schematic cross section of the mirror plate and the mirro hinges after the CMOS process and the postprocessing sacrificiallayer etch steps.

\section{Mirror Surface Characterization}

In order to qualify the aluminum mirror layer available from the IC process for optical applications and to investigate the surface modifications induced by the postprocessing etch sequence, we measured the surface roughness, the thickness of the native oxide formed on top of the Al-1\%Si layer, and the optical reflectance as a function of the wavelength of incident light, each before and after the postprocessing steps.

The surface rms roughness of aluminum test layers was determined from the surface profile taken by atomic force microscopy (AFM). Four sample wafers were prepared, each coated with different aluminum layers sputterdeposited on top of the plasmia-enhanced CVD (PECVD) silicon dioxide used as intermetal oxide in the CMOS process: Al-1\%Si at a thickness of $0.9 \mu \mathrm{m}$ at $250^{\circ} \mathrm{C}$ sputter temperature (No. 1), $0.3 \mu \mathrm{m}$ sputtered as close to room temperature as possible (No. 2) $0.3+0.6 \mu \mathrm{m}$ (double-pass 


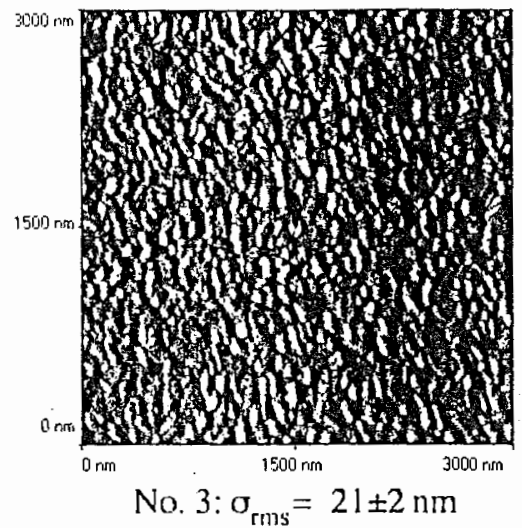

(a)

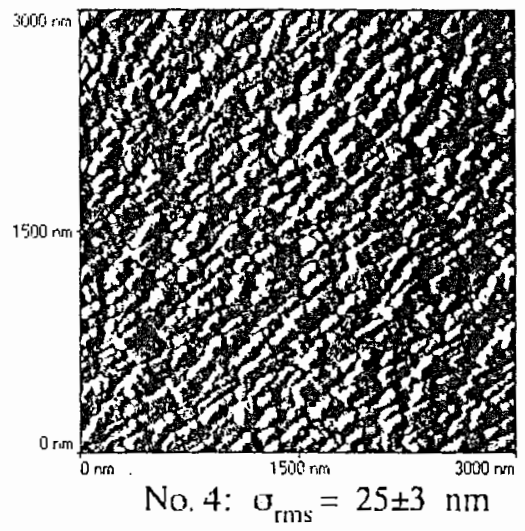

(b)

Fig. 6 Alomic force micrographs of test metallizations sputter-deposited in two subsequent passes of $0.3-$ and $0.6+\mu \mathrm{m}$ thickness at room temperature. The film surface as deposited (a) differs only slightly from the surlace after the passivation lithography and postprocessing sequence (b).

the test aluminum surfice sputter-deposited in two subsequent passes of $0.3-$ and $0.6-\mu \mathrm{m}$ thickness at room temperature is compared before and after postprocessing in order to evaluate the influence of the photolithography and etching procedure on the opticis properties.

Within the range of visible light. a sufficiently flat speetrum with a maximum reflectance of $88.5 \%$ was obtained, decreasing below $84 \%$ in the UV and neilr-infrared regimes. A reflectance enhanced by $1 \%$ in the visible range was obtained for at thin aluminum layer of $0.3-\mu \mathrm{m}$ thickness, also sputlered at room temperiture. The aluminum is highly reflective abuve a wivelength of $1000 \mathrm{~nm}$. This reflectance behavior agress with literiture datit for metallic aluminum with surfice and. pessibly. cren bulk oxidation if the samples." Nole that the reflectance of aluminum even under ultrahigh-vilcuum depositiun conditions ${ }^{10}$ does not exceed mixinum vilues of $93 \%$. The postprocessing results in a reflectince lowered by mot more than $2 \%$ in the visible and an insigniticant change for $\lambda>850 \mathrm{~nm}$.

In order to further investigite il the decreased reflectance could possibly be related to an increased layer thickness of native aluminum oxich on top of the samples, scanning Auger spectroscopy" wiss performed. Two samples were compared to determine the inlluence of the postprocessing on the aluminum films (sputer-deposited at room temperature): aluminum as deposited and after postprocess-

Table 1 Deposition and film properties of the samples characterized by atomic force microscopy.

\begin{tabular}{cccrr}
\hline Sample no. & $\begin{array}{c}\text { Layer } \\
\text { thickness } \\
(\mu \mathrm{m})\end{array}$ & $\begin{array}{c}\text { Deposition } \\
\text { temperature } \\
\left({ }^{\circ} \mathrm{C}\right)\end{array}$ & $\begin{array}{c}\sigma_{\text {rms }} \\
(\mathrm{nm})\end{array}$ & $\begin{array}{c}\text { Intrinsic } \\
\text { stress } \\
(\mathrm{MPa})\end{array}$ \\
\hline 1 & 0.9 & 250 & $53 \pm 5$ & +250 \\
2 & 0.3 & $=20$ & $12.5 \pm 1$ & -50 \\
3 & $0.3=0.6$ & $=20$ & $21 \pm 2$ & +60 \\
4 & $0.3=0.6$ & $=20$ & $25 \pm 3$ & +60 \\
\hline
\end{tabular}

ing. Their differentialted Auger spectra are shown in Fig. 8. The netallic aluminum peaks ( $K L L$ and $L M M$ ) and the oxygen of the native oxide are comparable, but a significant carbon contamination is fisund on the postprocessed surfalce.

The samples were then sputter-etched in situ and the Auger spectrum was lakien alter every $10 \mathrm{~s}$ of sputter time. With the elchback of the tilm, a depth profile of the relative altuminum, oxygen, and curbon content is obtained (Fig. 9). The surfite depth is cilculited for each material using the etch rates given in Table?

For the postprocissed sample, the oxygen distribution and, accordingly. the metallic aluminum concentration deselop dieper into the lilm. but the corresponding native aluminum passisation grew in thickness by not more than $0.8 \mathrm{~mm}$ during postprocening. The carbon contamination Wals 1 to + monolily ers thick and likely originated from the photolithographic step during the postprocessing sequence. This slightly increased passivation of aluminum can possibly explain the decreased reflectance described above.

\section{Results and Discussion}

The performance of the individual micromirrors was tested by measuring the angular deflection versus driving voltage. Using a UBM conlocial microscope. the deflection height is measured at two points of known distance on top of the mitror surface. from which the angular deflection is calculated. The result in Fig. 10 show's a threshold voltage $V_{t h}$ of $10.8 \mathrm{~V}$ for the full mirror deflection of $4.8 \mathrm{deg}$, in good agreement with the theoretical value of $11.7 \mathrm{~V}$ calculated from linear elasticity theory and a simplified geometry of the lower electrodes.

In order to demonstrate the CMOS compatibility of the double-pass metal actuator, a CMOS inverter is placed next to each pixel of the linear array (Fig. 4) to drive the individual mirrors and the corresponding landing electrodes. The inverter can be switched with $S-V$ data pulses. The two address electrodes underneath the mirror "wings" are connected to a constant wollige larger than $V_{1 h}$ and $O V$, 
Table 2 Etch rates and thickness of the aluminum passivation layers obtained by Auger spectroscopy.

\begin{tabular}{lccc} 
Malerial & $\begin{array}{c}\text { Etch rate } \\
(\mathrm{nm} / \mathrm{min})\end{array}$ & $\begin{array}{c}\text { Before } \\
\text { postprocessing }\end{array}$ & $\begin{array}{c}\text { Thickness (nm) } \\
\text { postprocessing }\end{array}$ \\
\hline $\mathrm{Al}$ (met.) & 20 & $\cdot$ & $\cdot$ \\
$\mathrm{Al}_{2} \mathrm{O}_{3}$ & 6 & 2.4 & $2.4-3.2$ \\
$\mathrm{C}$ & 3 & Not significantly \\
present & $0.4-1.2$ \\
\hline
\end{tabular}

plates and rectangular torsional hinges. ${ }^{12}$ Depending on the optical application, a torsional axis diagonal with respect to the row of the mirrors' may be preferred to a perpendicular axis of rotation.

\section{Conclusions}

It was shown that linear arrays of torsional micromirrors can be fabricated at low cost and integrated with on-chip circuitry using a CMOS process with double pass metallization.

Due to their high reflectance, CMOS Al-1\% Si layers are well suited for optical applications, and the smoothness of the surface is enhanced when the sputter temperature is reduced as much as the required step coverage allows. The postprocessing steps to release the aluminum actuator do not significantly degrade the optical properties of the aluminum surface: the passivation film on top of the metallic aluminum increases by not more than approximately $1 \mathrm{~nm}$, and the absolute reflectarce is lowered by a maximum of $2 \%$ to values between $83 \%$ and $89 \%$ in the spectral range of visible light. Consequently, the postprocessing is compatible with optical devices.

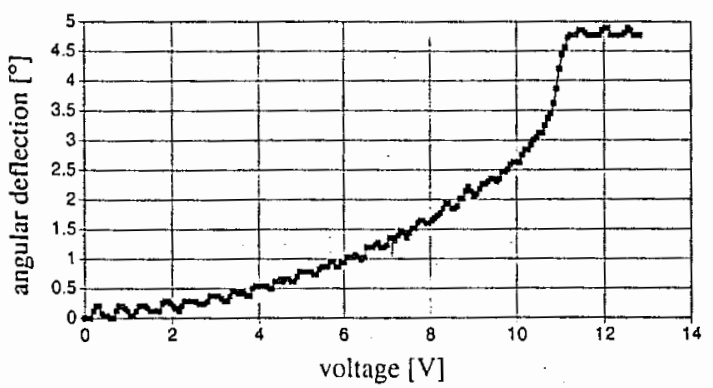

Fig. 10 Angular deflection versus driving voltage biasing the ad. dress electrode of the torsional mirrors shown in Fig. 4.

\section{Acknowledgments}

The authors are indebted to P. N. Sarro and H. Schellevis, DINES. Delit University of Technology for their work on implementing the double-piss metal process and for providing the CMOS and aluminum test film samples. We also thank L. Eng and M. Abplanalp for the atomic force micrographs. The reflectance measurements performed by GRETAG AG. Regensdorf, are gratefully acknowledged. E. Bolz contributed to the choice of the etch chemistry with some valuable discussions. This work was funded by the Swiss Federal Priority Program LESIT.

\section{References}

I. L. J. Hornbeck, "Digital light processing and MEMS: timely convergence for a bright fuiure." Proc. SPIE 2612. 2 (1995); preprint avail. able from Texas Instruments, Dallias. Texas.

2. C.W. Stument. D. A. Bortholder, V. Westerlind, J. W. Suh, N. I Mirluf, and G. T. A. Kovacs, "Fiexible, dry-released process for aluminum elactrustatic actuators." I. Ahichelectromech. Syst. 3(3), Yy)-96 (1994)

3. K. E. Mattson, "Surface micronlachined scianning mirrors," Microchectranic Eng. 19. 199-20+11992)

t. V. P. Jiecklin. C. Linder. N. F. de Rouij. J.M. Moret, and R. vuilleumier. "Line-atudressible torsional micronimors for light modulator artays," Sen.rons and Achators a $+1-42,324-329$ (1994)

5. ‥ C. Tien, O. Solgaard. M.H. Kiang, M. Daneman, K. Y. Lau, and R. S. Muller, "Surface-micromathined mirrors for laser-beam positioning." in Digess if Technicul Pulers. The 8 hh Intermational Conf.

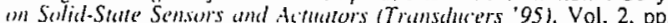
352-355, Stokholm. Sueden (1905).

6. AI B. Fischer. H. Graef and W" von Münch "Electrostatically de-

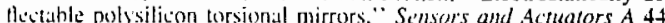
si-89 (190)+1).

7. J. Bühter I Funt F-P Stainer P M Sarro and H B.jtes "Double pars metillizalion for CNiOS aluminum artuators." in Digest of Tech.

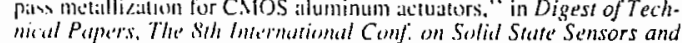

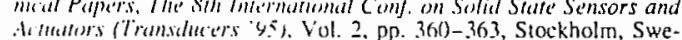
Alitedrats

Wham No. 17668, Riedel-dithien. Sect/c, Germany (1995).

9. P. A. Flims. "Principles and applications of watter curvature techniyues fir stress meatsurements in thin films." Wat. Re's. Soc. Symp Prov: $130+11-50(1989$

10. D. Y. Snith. E. Shiles, and M. Wnokuti, "The optical properties of metallic altuminum," in Illmellonk of Oprical Comstants of Solids, pp.

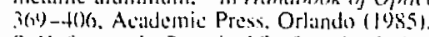

11. S. Hofinatnn. in Pratical Surfure Amblywis, D. Briggs and M. P. Seah

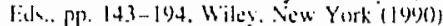

12. J. Funk. J. G. Korsink. M. Büchlold, J. Bühicr, and H. Baltes, "Conpled 30 thermerelectro-mechanical simulations of microactua-

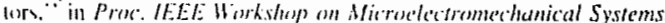
pp. 133-138. San Dieg". CA (1496)

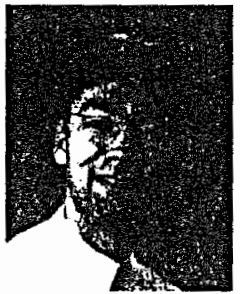

Johannes Bühler received the diploma degree in physics from the University of Karlsruhe. Germany, in 1992. He is currently pursuing the $\mathrm{PhD}$. degree at the Swiss Federal Institute of Technology (ETH) in Zurich. His research activities in clude the design, fabrication, and characterization of thermal and electrostatic microactuators.

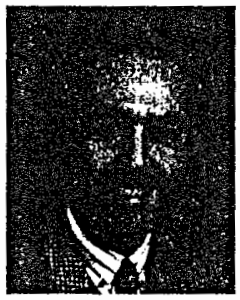

Franz-Peter Steiner recelved his diploma in physics and his PhO from the Swiss Federal institute of Technology (ETH Zurich) in 1985 and 1990 , respectively. Aiter several years in industry, last as manager of a product line of semiconductor process equipment, he returned to ETH as a program and project leader. His research interests include design and simuiation of microelectromechanical systems. $\mathrm{He}$ is head of the microactuators and the chemical sensors group and deputy director of the Swiss priority 